\section{International Scientific Journal Theoretical \& Applied Science}

p-ISSN: 2308-4944 (print) e-ISSN: 2409-0085 (online)

Year: $2018 \quad$ Issue: $01 \quad$ Volume: 57

Published: $30.01 .2018 \quad$ http://T-Science.org

SECTION 31. Economic research, finance, innovation, risk management.
Malahat Omar Panahaliyeva Associate Professor of the Department «World Economics and Marketing» of the Sumgayit State University

Shafa Tiflis Aliyev Doctor of Economic Sciences, Professor of the Department «World Economics and Marketing» of Sumgait State University, Member of the Expert Council on Economic Sciences the Higher Attestation Commission under the President of the Azerbaijan Republic

\title{
STRATEGIC OBJECTIVES OF DIVERSIFICATION OF FOREIGN TRADE TURNOVER OF AZERBAIJAN IN THE GLOBAL WORLD
}

Abstract: The article examines the strategic tasks of diversifying the foreign trade of Azerbaijan in the global world. The main partner countries and their share in the foreign trade turnover of Azerbaijan are analyzed with this purpose. The share of the main partners in the import and export of Azerbaijan by the results of 2016 is considered. The share of large countries of the world in imports and, in general, in Azerbaijan's general trade turnover is studied. The geographic structure of Azerbaijan's imports and exports is given in 2016. Dynamics of the foreign trade turnover of Azerbaijan for 1991-2016 is given. The foreign trade turnover of Azerbaijan with a group of countries of the world and the import structure for 2012-2016 are considered. Commodity groups reveal the essence of Azerbaijan's import structure for 2016 in different spheres of activity of the national economy and the structure of Azerbaijan's exports for 2012-2016, for 2016. A number of recommendations and proposals on the strategic tasks of diversification of Azerbaijan's foreign trade in the global world are generalized and given.

Key words: Azerbaijan, foreign trade turnover, structure of foreign trade turnover, export-import of Azerbaijan, export potential of Azerbaijan, strategic goals of diversification of foreign trade turnover, Azerbaijan in the global world.

Language: Russian

Citation: Panahaliyeva MO, Aliyev ST (2018) STRATEGIC OBJECTIVES OF DIVERSIFICATION OF FOREIGN TRADE TURNOVER OF AZERBAIJAN IN THE GLOBAL WORLD. ISJ Theoretical \& Applied Science, 01 (57): 209-219.

Soi: http://s-o-i.org/1.1/TAS-01-57-35 Doi: crossef https://dx.doi.org/10.15863/TAS.2018.01.57.35

\section{СТРАТЕГИЧЕСКИЕ ЗАДАЧИ ДИВЕРСИФИКАЦИИ ВНЕШНЕТОРГОВОГО ОБОРОТА АЗЕРБАЙДЖАНА В ГЛОБАЛЬНОМ МИРЕ}

Аннотация: В статье исследованы стратегические задачи диверсификаичи внешнеторгового оборота Азербайджана в глобальном мире. С этой иелью анализированы основные страны-партнеры и их доля во внешнеторговом обороте Азербайджана. Рассмотрена доля основных партнеров в импорте и экспорте Азербайджана по итогам 2016 года. Исследована доля крупных стран мира в импорте и, в целом в общеторговом обороте Азербайджана. Дана географическая структура импорта и экспорта Азербайджана по итогам 2016 года. Дана динамика внешнеторгового оборота Азербайджана за 1991 2016 годы. Рассмотрен внешнеторговый оборот Азербайджана с группой стран мира и структура импорта за 2012-2016 годы. Раскрыта сущность структуры импорта Азербайджана за 2016 год по разным сферам деятельности национальной экономики и структура экспорта Азербайджана за 2012-2016 годы, по товарнымм группам за 2016 год.

Обобщен и дан ряд рекомендащий и предложений по стратегическим задачам диверсификации внешнеторгового оборота Азербайджана в глобальном мире.

Ключевые слова: Азербайджан, внешнеторговый оборот, структура внешнеторгового оборота, экспорт-импорт Азербайджана, экспортный потенциал Азербайджана, стратегические цели диверсификации внешнеторгового оборота, Азербайджан в глобальном мире.

\section{Introduction}

В условиях глобализации и расширения масштаба глобальных экономических влияний нарастает роль и место внешнеторгового оборота в стране. Азербайджан, являясь странойэкспортером сырой нефти и нефтепродуктов в 
связи с негативными последствиями мирового финансового кризиса и снижения цен на нефть в мировом рынке, за последние годы испытывал серьезные трудности [1;2]. Уменьшились национальные доходы и нефтяные выручки, нарушилась стабильность финансово-банковской системы, закрылись примерно 10 банков страны, а национальная валюта - манат подверглась двукратной девальвации. Все эти факторы обуславливают расширение развития ненефтяного экспорта и максимально эффективного использования экспортного потенциала ненефтяного секторов страны [3;4;5].

\section{Materials and Methods}

Отметим, что в Азербайджане за последние годы разработаны и осуществляются исторические и стратегические документы моделирования развития национальной экономики и интенсификации развития ненефтяного экспорта [6;7]. Более того, ведется целенаправленная работа по повышению производительности и объему продукции ряда конкурентоспособных и икспортноориентированных секторов экономики страны (химия, нефтехимия, металлургия, информационно-коммуникационные технологии, сферы сельского хозяйства и агросектора, туризма, транспорт и прочее).

В стране разработана сбалансированная внешнеторговая политика, с учетом глобальных тенденций, изменения торговых правил в мирохозяйственной системе $[8 ; 9 ; 10 ; 11 ; 12 ; 13]$. Совершенствуются действующие механизмы внешнеторговой деятельности, структура экспортных операций и эффективное использование валютных средств, усиливается валютный контроль [14]. В Азербайджане ведется активная работа по диверсификации внешнеэкономических связей и структуры внешнеторгового оборота страны. Имеется внешнеэкономическая связь со свыше 140 странами мира и части этих стран удалось установить стратегические торговоэкономические связи и узы взаимного сотрудничества.

На Рисунке 1 даны первые 10 стран, которые занимают особое место во внешнеторговом обороте Азербайджана по итогам 2016 года.

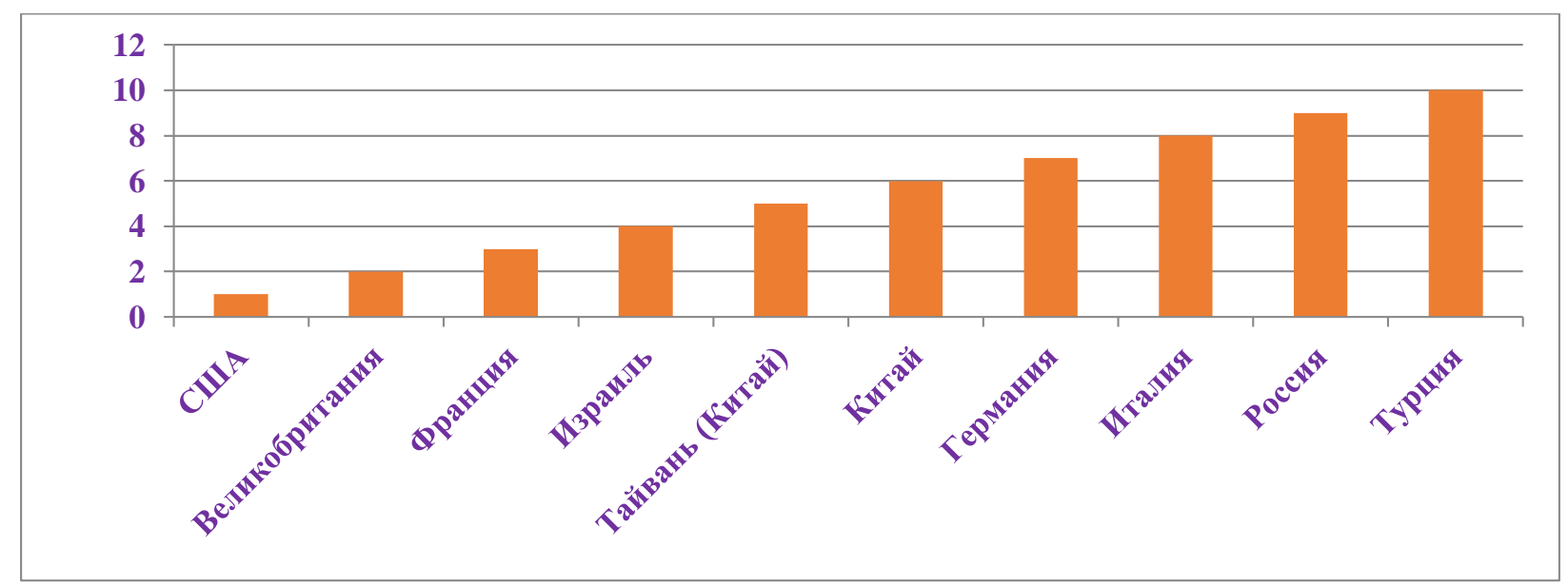

Рисунок 1 - Основные страны-партнеры Азербайджана во внешнеторговом обороте, первые десять мест, 2016 год. (подготовлено авторами на основе материалов Государственного Статистического Комитета Азербайджанской Республики, http://www.stat.gov.az).

А на Рисунке 2 дана доля основных мировых стран-партнеров Азербайджана во внешней торговле по итогам 2016 года, где доля Турции составляет - 13,1 \%, далее идут: Российская Федерация - 11,6 \%, Италия - 10,7 \%, Германия $5,7 \%$, Китай $-5,5 \%$ и др. 


\begin{tabular}{l|lr|ll|ll} 
& ISRA (India) & $=\mathbf{1 . 3 4 4}$ & SIS (USA) & $=\mathbf{0 . 9 1 2}$ & ICV (Poland) & $\mathbf{= 6 . 6 3 0}$ \\
Impact Factor: & ISI (Dubai, UAE) $=\mathbf{0 . 8 2 9}$ & PUHЦ (Russia) $=\mathbf{0 . 2 0 7}$ & PIF (India) & $=\mathbf{1 . 9 4 0}$ \\
& GIF (Australia) & $=\mathbf{0 . 5 6 4}$ & ESJI (KZ) & $=\mathbf{4 . 1 0 2}$ & IBI (India) & $=\mathbf{4 . 2 6 0}$ \\
& JIF & $=\mathbf{1 . 5 0 0}$ & SJIF (Morocco) $=\mathbf{2 . 0 3 1}$ & & \\
\hline
\end{tabular}

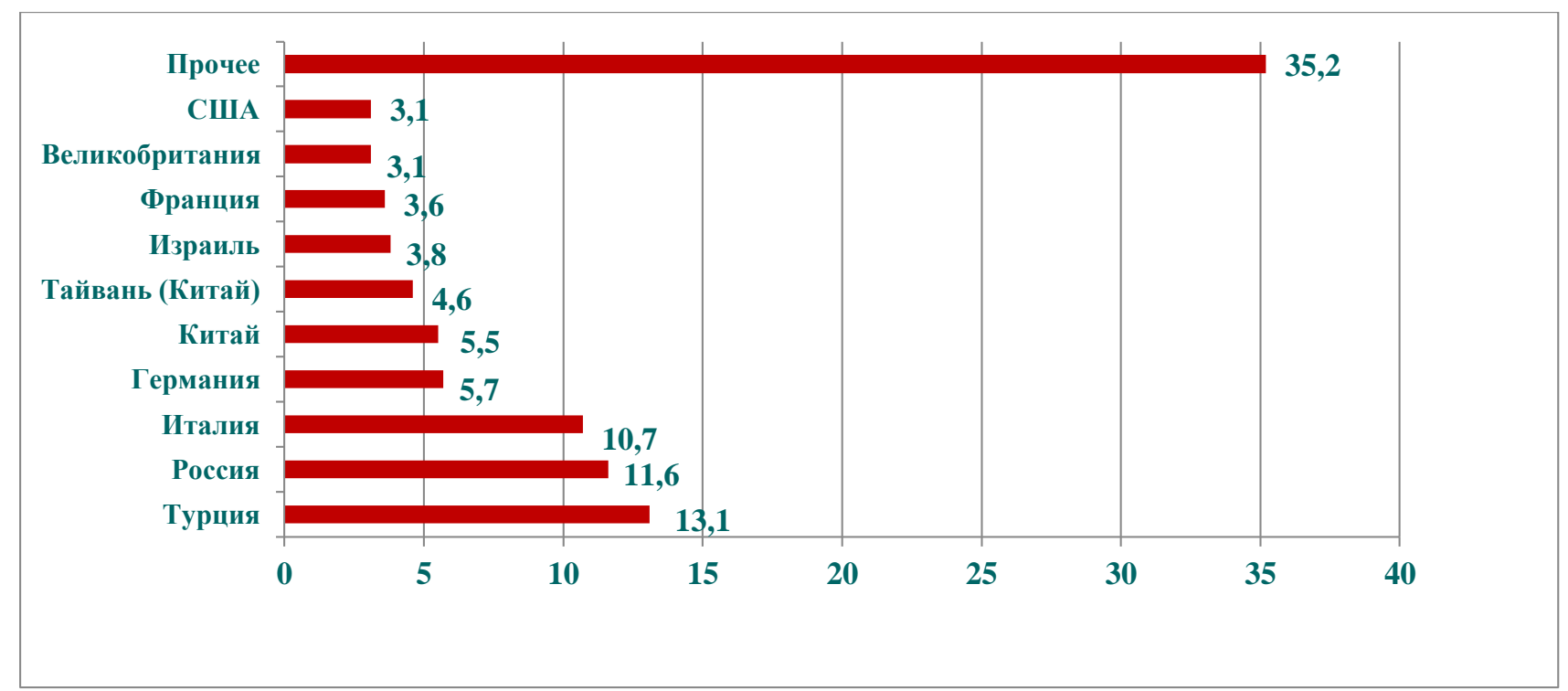

Рисунок 2 - Доля основных мировых стран-партнеров Азербайджана во внешней торговле по итогам 2016 года, в \%. (подготовлено авторами на основе материалов Государственного Статистического Комитета Азербайджанской Республики, http://www.stat.gov.az).

На Рисунке 3 дана доля основных партнеров в импорте Азербайджана по итогам 2016 года, где Россия имеет самые высокие показатели - $19 \%$, следующие места занимают: Турция - $14 \%$, Китай $-8 \%$, Великобритания и США - $6 \%$, Германия - 5 $\%$ и др.

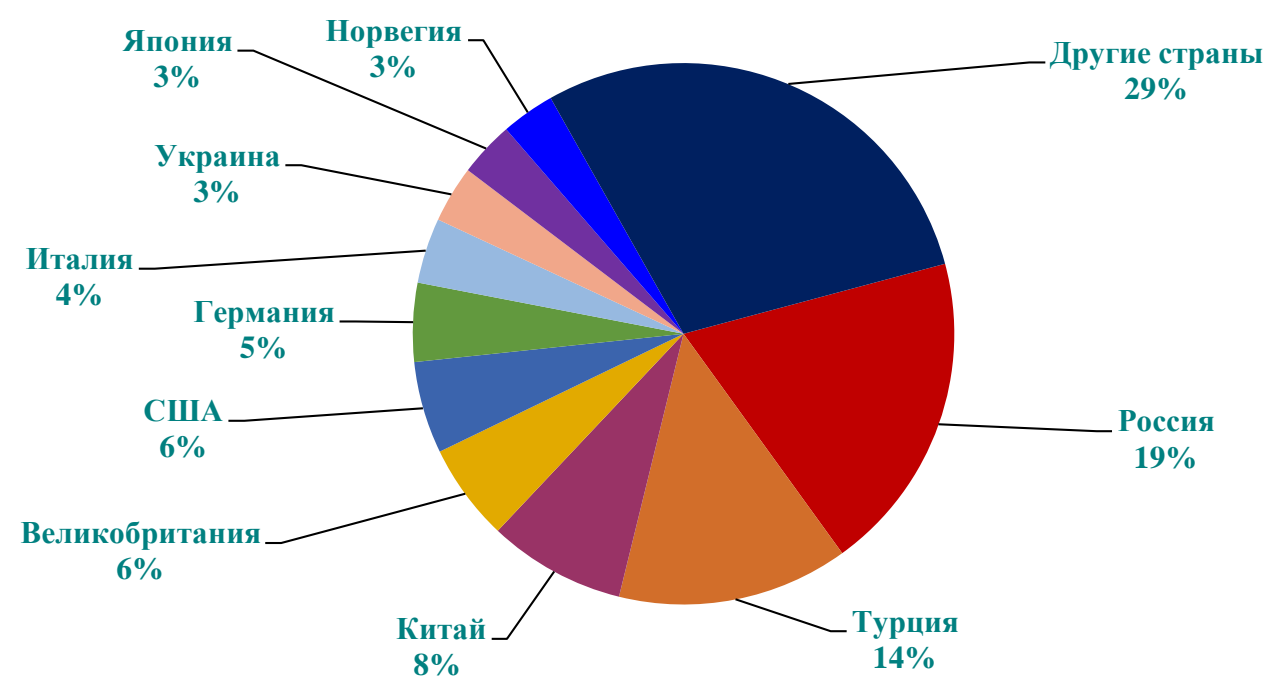

Рисунок 3- Доля основных партнеров в импорте Азербайджана по итогам 2016 года, в \%. (подготовлено авторами на основе материалов Государственного Статистического Комитета Азербайджанской Республики, http://www.stat.gov.az).

На Рисунке 4 даны основные партнеры Азербайджана в экспорте за 2016 год, где лидерует Италия - 17 \%, Турция - $12 \%$, Тайвань (Китай) -9
\%, Израиль и Германия - 7 \%, Франция, Индия и Россия $-5 \%$, Грузия $-4 \%$ и др. 


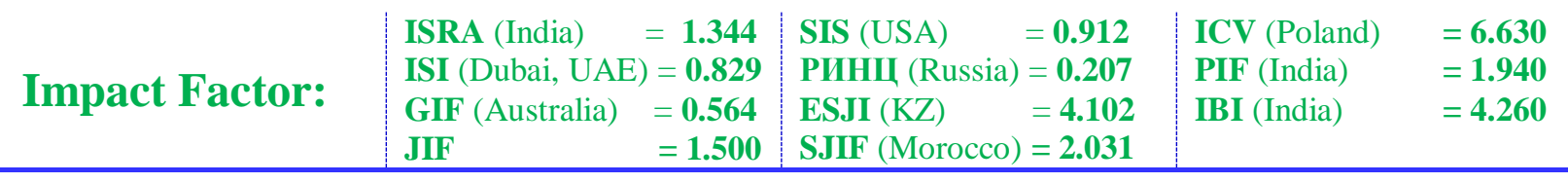

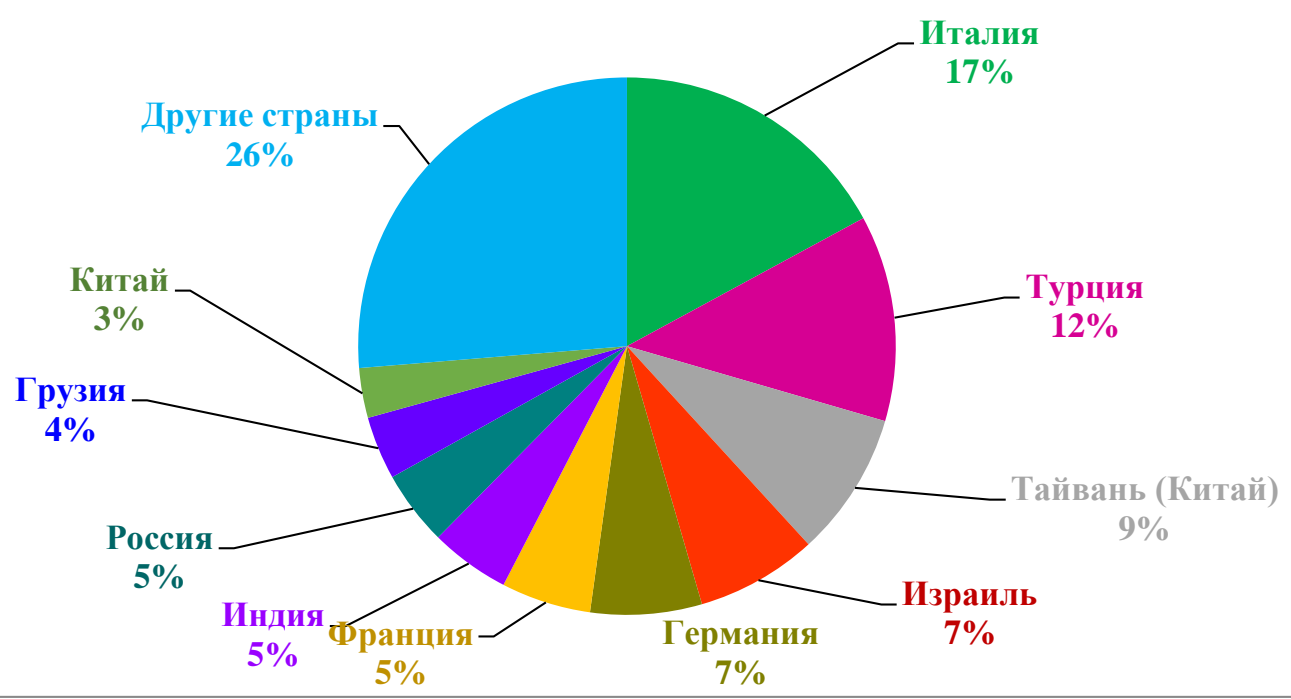

Рисунок 4 - Основные партнеры Азербайджана в экспорте за 2016 год, в \%, 2016 г. (подготовлено авторами на основе материалов Государственного Статистического Комитета Азербайджанской Республики, http://www.stat.gov.az).

Отметим, что Азербайджан уделяет особое внимание развитию внешнеэкономических связей со странами, которые входят в отдельные региональные организации и группы стран мира. На Рисунке 5 дана доля группы стран мира в импорте Азербайджана за 2016 год.

Организация Экономического Сотрудничества и.

АСЕАН

Ассоциация Свободной Торговли Европы

Организация Страны Азии и Тихого океана

Организация Исламского Сотрудничества

ОПЕК

ОПЕК
ГУАМ

Организация Экономического Сотрудничества

ОЧЭС

Европейский Союз

Стран Независимых Государств

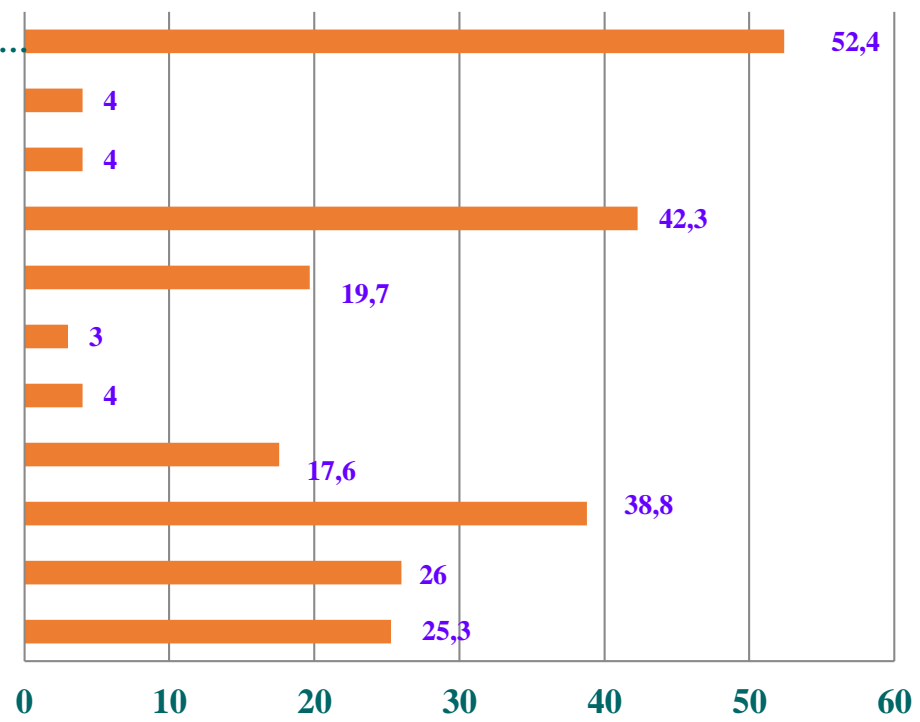

Рисунок 5 - Доля группы стран мира в импорте Азербайджана за 2016 годы, в \%. (подготовлено авторами на основе материалов Государственного Статистического Комитета Азербайджанской Республики, http://www.stat.gov.az).

А на Рисунке 6 дана доля группы стран мира в общем торговом обороте Азербайджана за 2016 год. 


\begin{tabular}{l|lr|ll|ll} 
& ISRA (India) & $=\mathbf{1 . 3 4 4}$ & SIS (USA) & $=\mathbf{0 . 9 1 2}$ & ICV (Poland) & $=\mathbf{6 . 6 3 0}$ \\
Impact Factor: & ISI (Dubai, UAE) $=\mathbf{0 . 8 2 9}$ & PUHЦ (Russia) $=\mathbf{0 . 2 0 7}$ & PIF (India) & $=\mathbf{1 . 9 4 0}$ \\
& GIF (Australia) & $\mathbf{0 . 5 6 4}$ & ESJI (KZ) & $=4.102$ & IBI (India) & $=\mathbf{4 . 2 6 0}$ \\
& JIF & $=\mathbf{1 . 5 0 0}$ & SJIF (Morocco) & $=\mathbf{2 . 0 3 1}$ & & \\
\hline
\end{tabular}

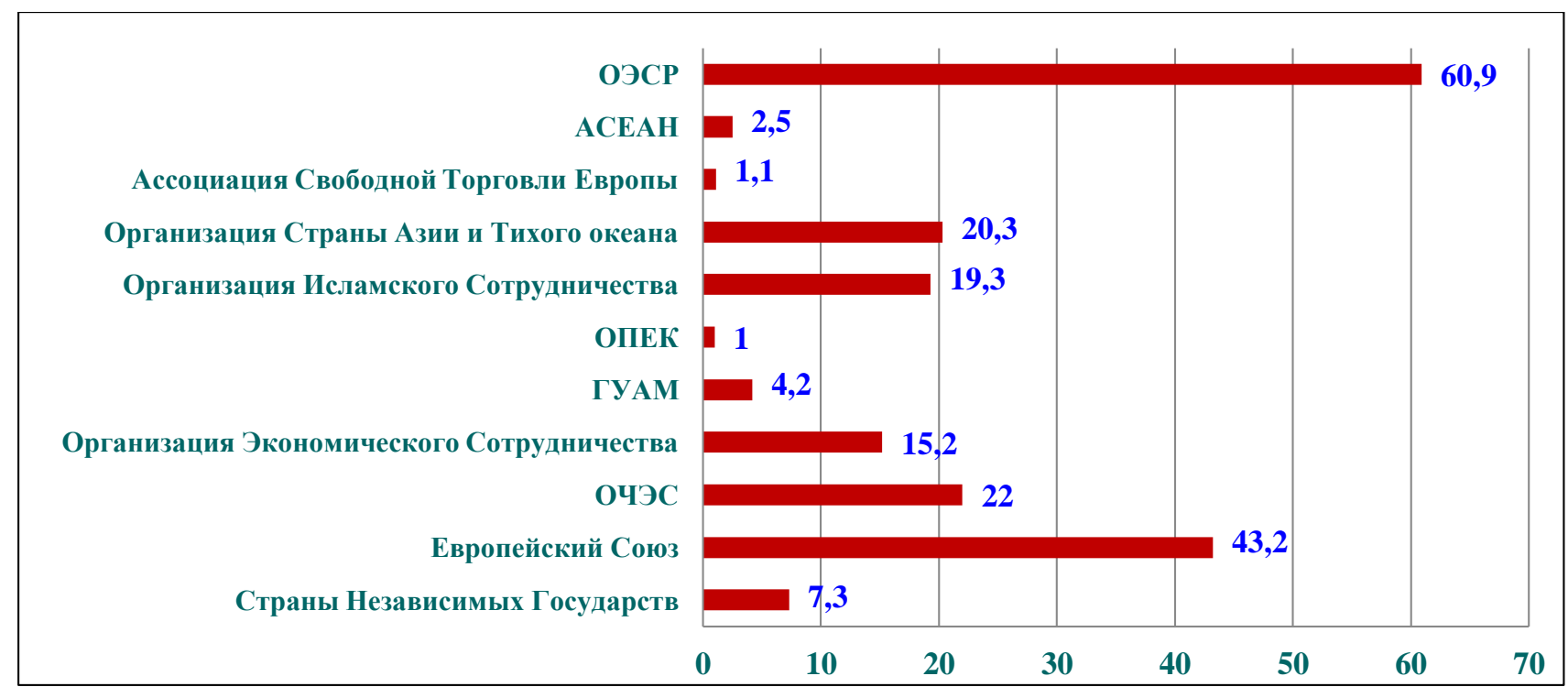

Рисунок 6 - Доля группы стран мира в общем торговом обороте Азербайджана за 2016 годы, в \%. (подготовлено авторами на основе материалов Государственного Статистического Комитета Азербайджанской Республики, http://www.stat.gov.az).

На Рисунке 7 дана географическая структура импорта Азербайджана по итогам 2016 года.

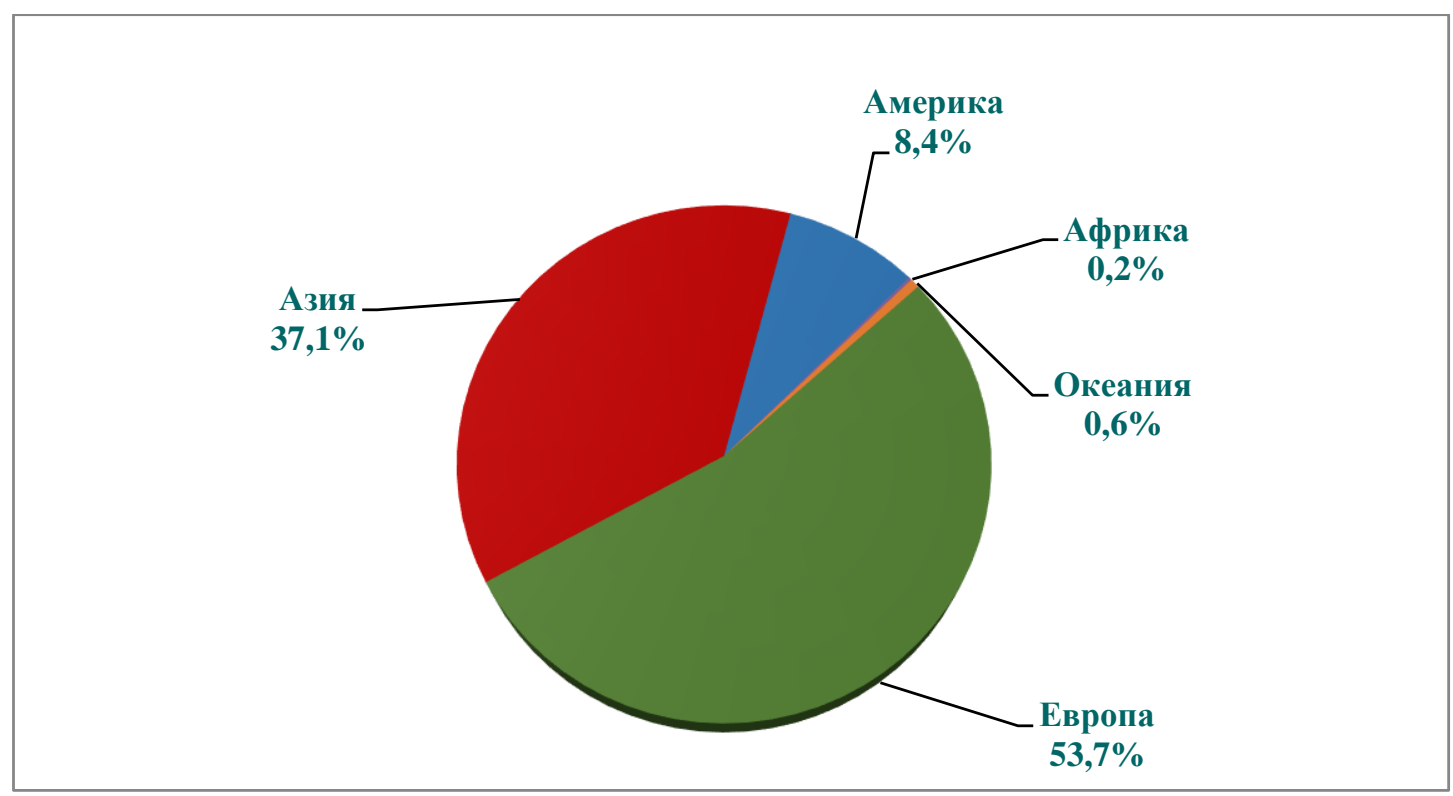

Рисунок 7 - Географическая структура импорта Азербайджана по итогам 2016 года. (подготовлено авторами на основе материалов Государственного Статистического Комитета Азербайджанской Республики, http://www.stat.gov.az).

На Рисунке 8 отражена географическая структура экспорта Азербайджана по итогам 2016 года, где основная доля принадлежит странам Европы 49,8 \% и Азии 46,1\%. 


\begin{tabular}{l|lr|ll|ll} 
& ISRA (India) & $=\mathbf{1 . 3 4 4}$ & SIS (USA) & $=\mathbf{0 . 9 1 2}$ & ICV (Poland) & $=\mathbf{6 . 6 3 0}$ \\
Impact Factor: & ISI (Dubai, UAE) & $=\mathbf{0 . 8 2 9}$ & PUHL (Russia) & $=\mathbf{0 . 2 0 7}$ & PIF (India) & $=\mathbf{1 . 9 4 0}$ \\
& GIIF (Australia) & $\mathbf{0 . 5 6 4}$ & ESJI (KZ) & $=\mathbf{4 . 1 0 2}$ & IBI (India) & $\mathbf{4 . 2 6 0}$ \\
& JIF & $=\mathbf{1 . 5 0 0}$ & SJIF (Morocco) & $=\mathbf{2 . 0 3 1}$ & & \\
\hline
\end{tabular}

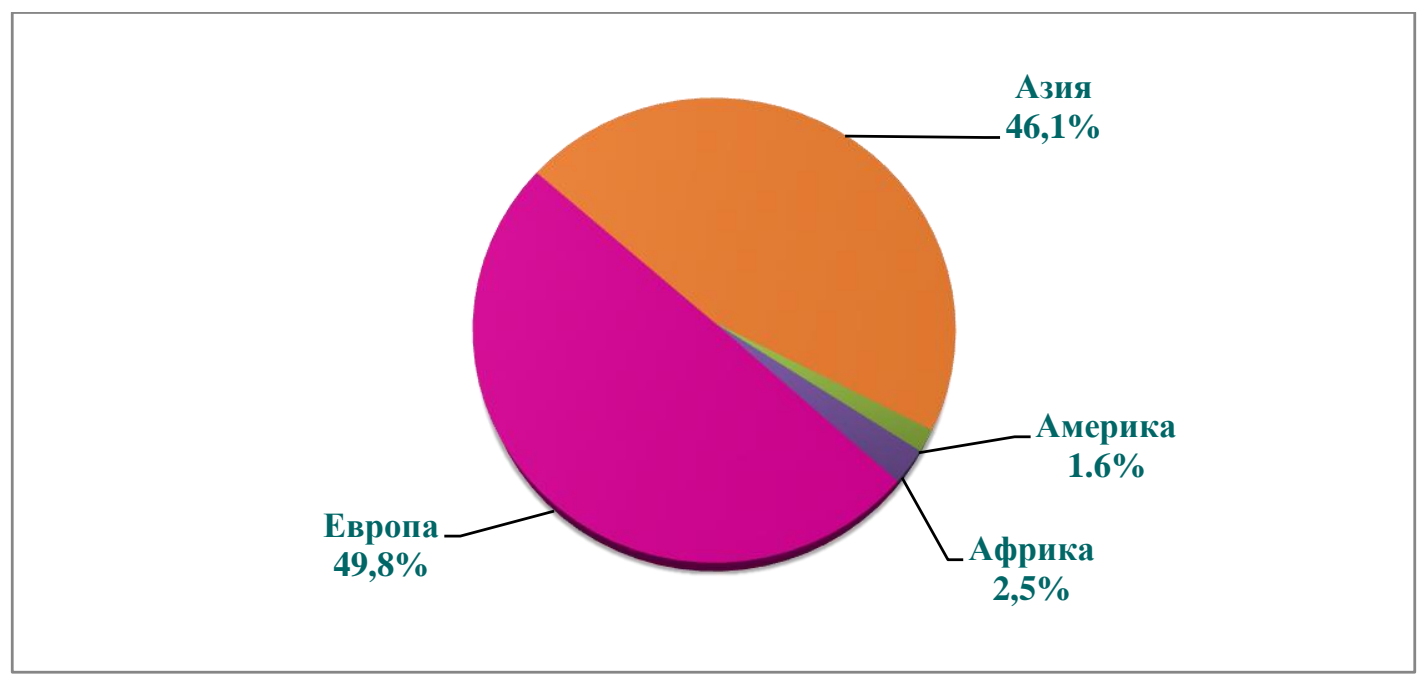

Рисунок 8 - Географическая структура экспорта Азербайджана по итогам 2016 года. (подготовлено авторами на основе материалов Государственного Статистического Комитета Азербайджанской Республики, http://www.stat.gov.az).

За последнее 10-15 лет, благодаря существенному увеличению нефтяного экспорта, объем общего внешнеторгового оборота Азербайджана продемонстрировал серьезный рост и в 2008 году был зафиксирован рекордный объем внешнеторгового оборота Азербайджана за всю его историю - 54,9 млрд. долл. США, при цене на нефть, за 1 баррель, 147 долл. США на мировом рынке. Но, как мы отметили ранее, в результате негативных последствий финансового кризиса в мире и снижения цен на нефть на мировом рынке за последнее годы (2010-2016), общий объем внешнеторгового оборота снизился в 2,5 раза, в том числе экспорт снизился в 3,6 раза, что, соответственно, составило 21,7 млрд. долл. США и 13,1 млрд. долл. США.

На Рисунке 9 дана динамика внешнеторгового оборота Азербайджана за 19912016 годы.

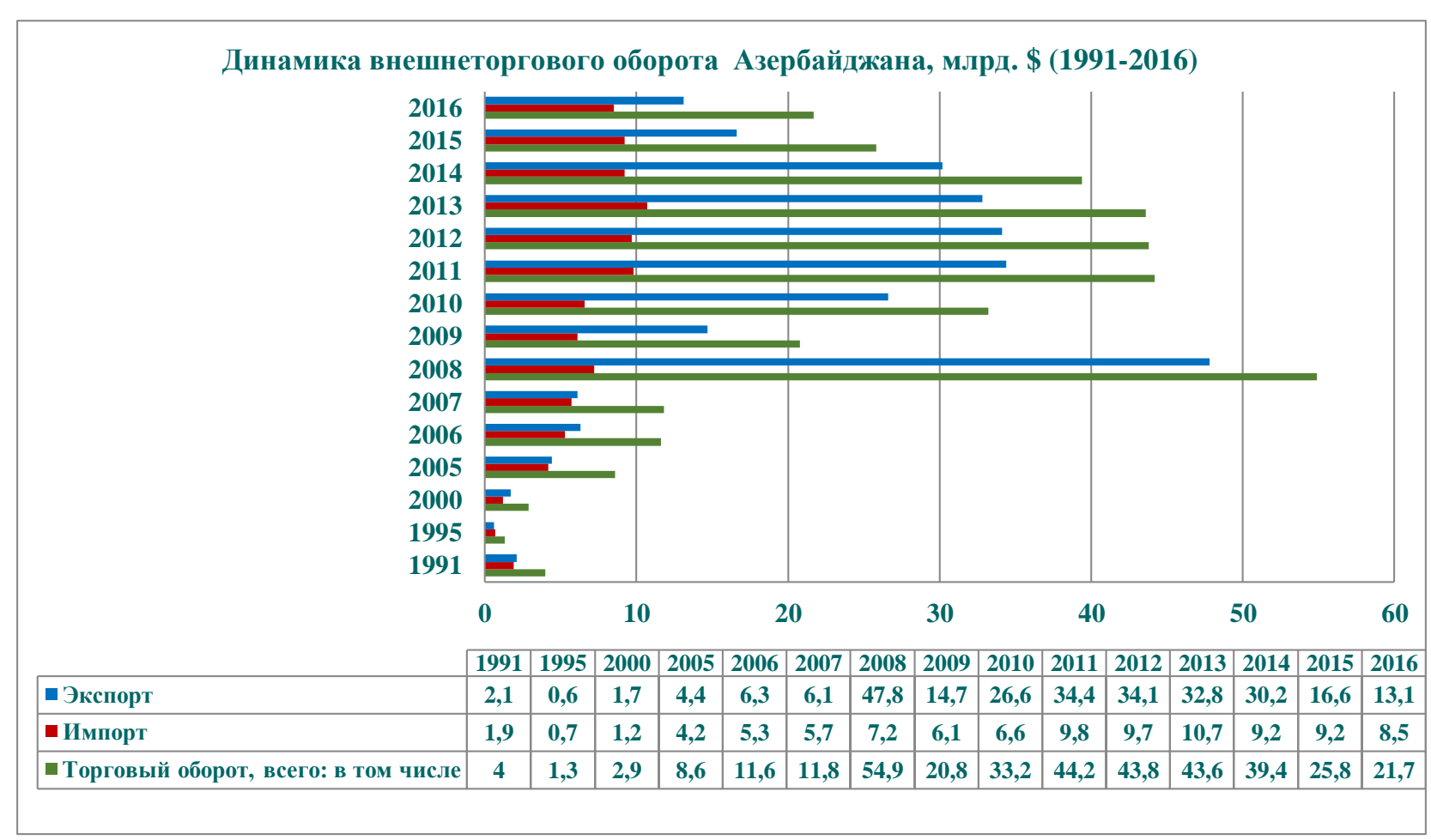

Рисунок 9 - Динамика внешнеторгового оборота Азербайджана, млрд. долл. США, 1991-2016 годы (подготовлено авторами на основе материалов Государственного Статистического Комитета Азербайджанской Республики, http://www.stat.gov.az). 


\begin{tabular}{|c|c|c|c|c|c|c|}
\hline \multirow{4}{*}{ Impact Factor: } & ISRA (India) & $=1.344$ & SIS (USA) & $=0.912$ & ICV (Poland) & $=6.630$ \\
\hline & ISI (Dubai, UAE & $=0.829$ & РИНЦ (Russia & $=0.207$ & PIF (India) & $=1.940$ \\
\hline & GIF (Australia) & $=0.564$ & ESJI (KZ) & $=4.102$ & IBI (India) & $=4.260$ \\
\hline & JIF & $=1.500$ & SJIF (Morocco & $=2.031$ & & \\
\hline
\end{tabular}

На Рисунке 10 отражены показатели внешнеторгового оборота Азербайджана с группой стран мира за 2012-2016 годы.

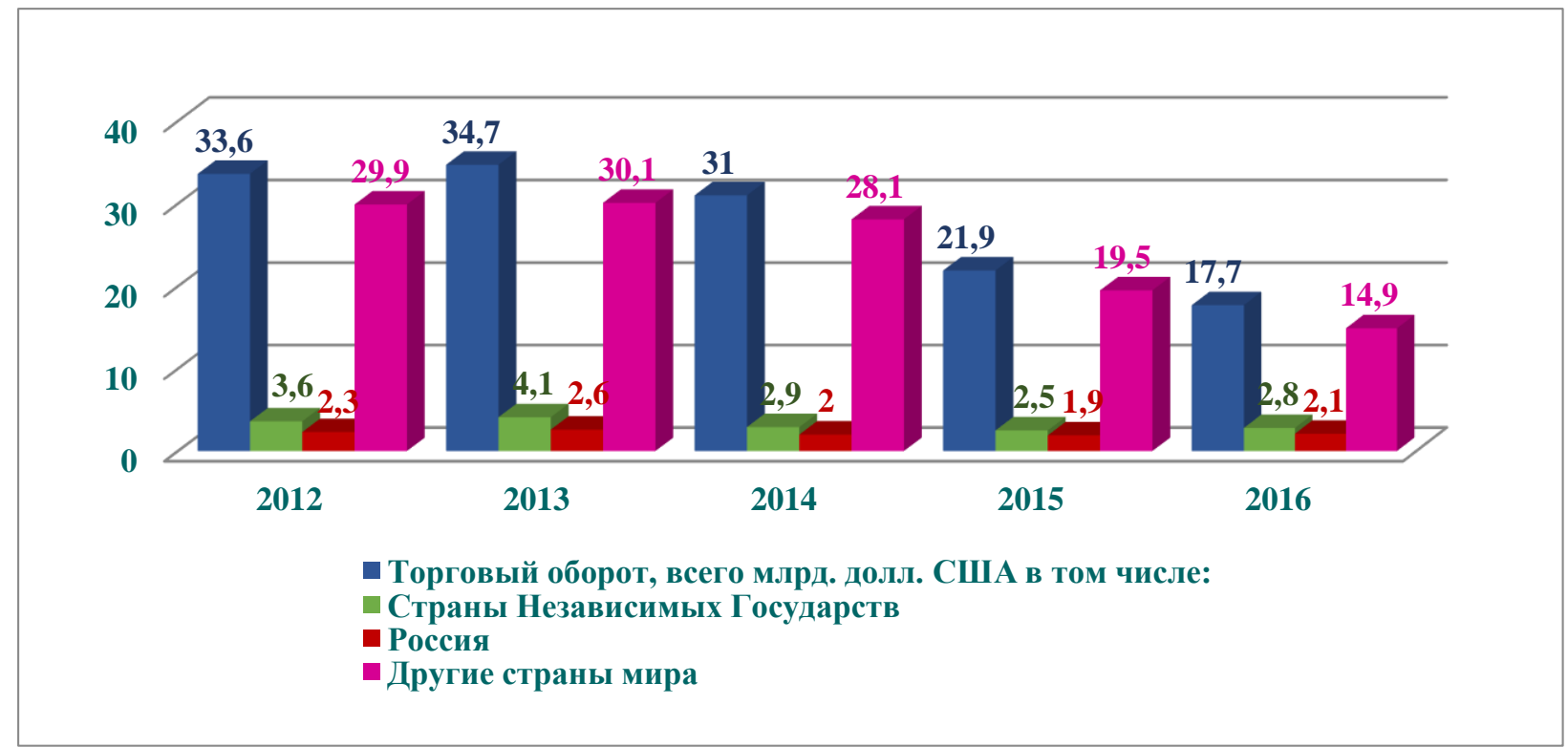

Рисунок 10 - Внешнеторговый оборот Азербайджана с группой стран мира, 2012-2016 годы, млрд. долл. США (подготовлено авторами на основе материалов Государственного Статистического Комитета Азербайджанской Республики, http://www.stat.gov.az).

Следует подчеркнуть, что для обеспечения экономической безопасности, особенно для развития промышленного сектора, формирования серьезного задела по укреплению продовольственной безопасности, Азербайджан импортирует необходимые машины и механизмы, продовольственные продукции, в том числе пшеницу. На Рисунке 11 дана структура импорта Азербайджана за 2012-2016 годы. 


\begin{tabular}{l|lr|ll|ll} 
& ISRA (India) & $=\mathbf{1 . 3 4 4}$ & SIS (USA) & $=\mathbf{0 . 9 1 2}$ & ICV (Poland) & $=\mathbf{6 . 6 3 0}$ \\
Impact Factor: & ISI (Dubai, UAE) $=\mathbf{0 . 8 2 9}$ & PUHЦ (Russia) $=\mathbf{0 . 2 0 7}$ & PIF (India) & $=\mathbf{1 . 9 4 0}$ \\
& GIF (Australia) & $\mathbf{0 . 5 6 4}$ & ESJI (KZ) & $=\mathbf{4 . 1 0 2}$ & IBI (India) & $=\mathbf{4 . 2 6 0}$ \\
& JIF & $=\mathbf{1 . 5 0 0}$ & SJIF (Morocco) & $=\mathbf{2 . 0 3 1}$ & & \\
\hline
\end{tabular}

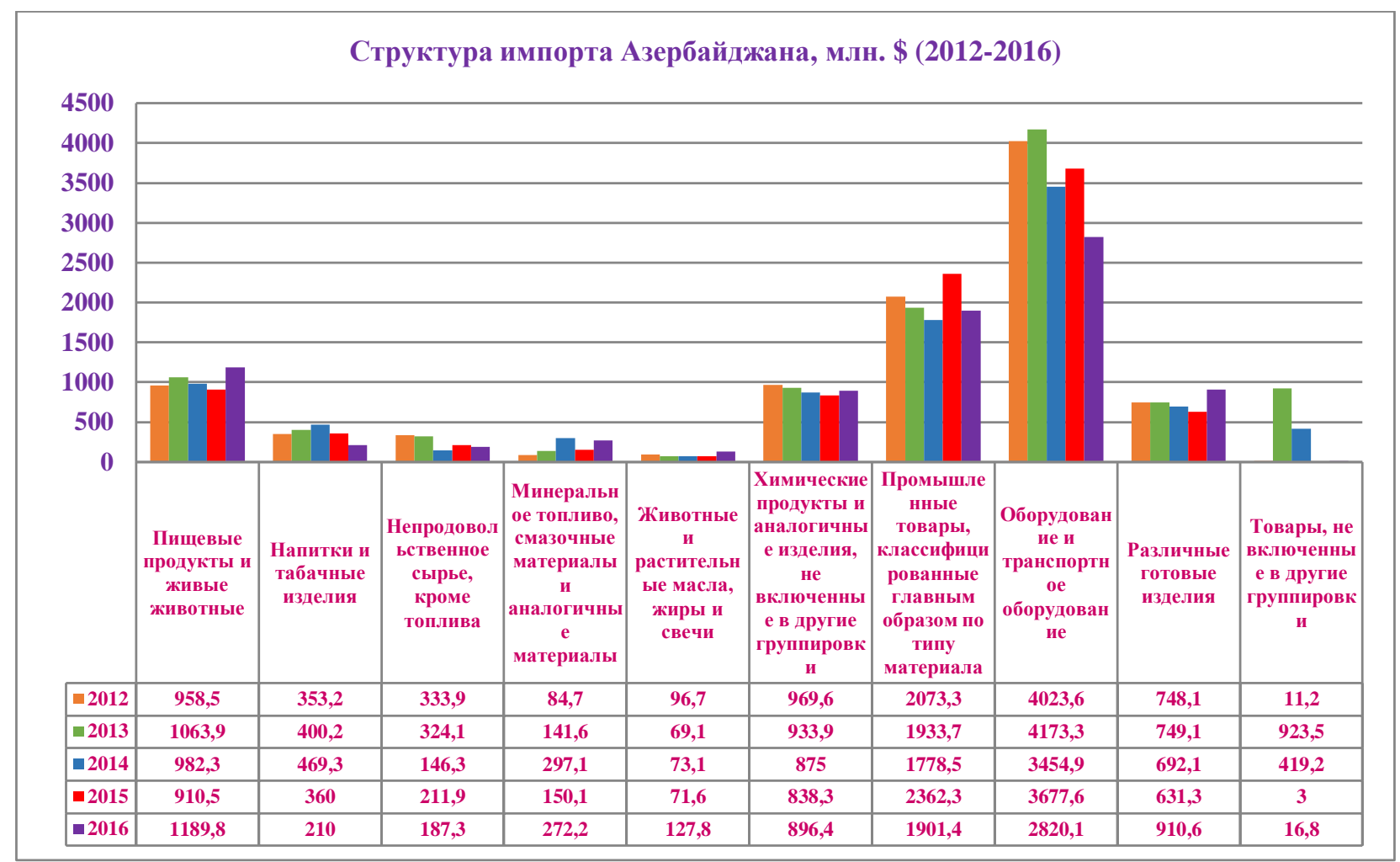

Рисунок 11 - Структура импорта Азербайджана за 2012-2016 годы, млн. долл. США (подготовлено авторами на основе материалов Государственного Статистического Комитета Азербайджанской Республики, http://www.stat.gov.az).

А на Рисунке 12 отражена структура импорта Азербайджана за 2016 год в процентах по разным сферам деятельности национальной экономики.

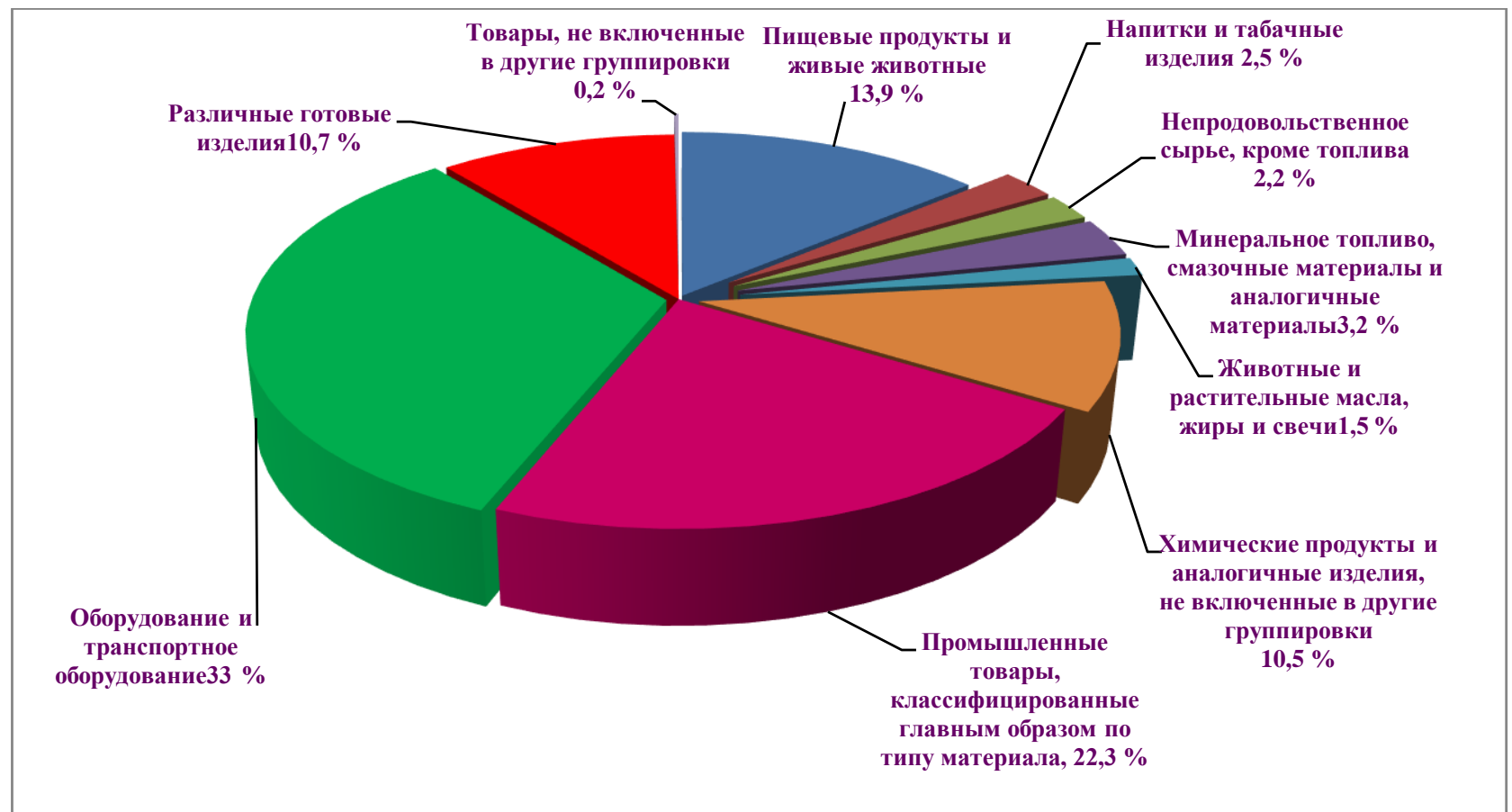

Рисунок 12 - Структура импорта Азербайджана за 2016 год по разным сферам деятельности национальной экономики, в \% (подготовлено авторами на основе материалов Государственного Статистического Комитета Азербайджанской Республики, http://www.stat.gov.az). 


\begin{tabular}{|c|c|c|c|c|c|c|}
\hline Impact Factor: & $\begin{array}{l}\text { ISRA (India) } \\
\text { ISI (Dubai, UAE } \\
\text { GIF (Australia) } \\
\text { JIF }\end{array}$ & $\begin{array}{r}=1.344 \\
=0.829 \\
=0.564 \\
=1.500\end{array}$ & $\begin{array}{l}\text { SIS (USA) } \\
\text { PИНЦ (Russia) } \\
\text { ESJI (KZ) } \\
\text { SJIF (Morocco) }\end{array}$ & $\begin{array}{l}=0.912 \\
=0.207 \\
=4.102 \\
=2.031\end{array}$ & $\begin{array}{l}\text { ICV (Poland) } \\
\text { PIF (India) } \\
\text { IBI (India) }\end{array}$ & $\begin{array}{l}=6.630 \\
=1.940 \\
=4.260\end{array}$ \\
\hline
\end{tabular}

Как видно, по Рисунку 12 в импорте Азербайджана большая доля принадлежит продукциям машиностроения, транспортным оборудованиям - 33 \%, продукции которых Азербайджан вынужден приобрести для усиления материально-технической базы и оснащенности отдельных секторов экономики страны.

На Рисунке 13 дана структура экспорта Азербайджана за 2012-2016 годы.

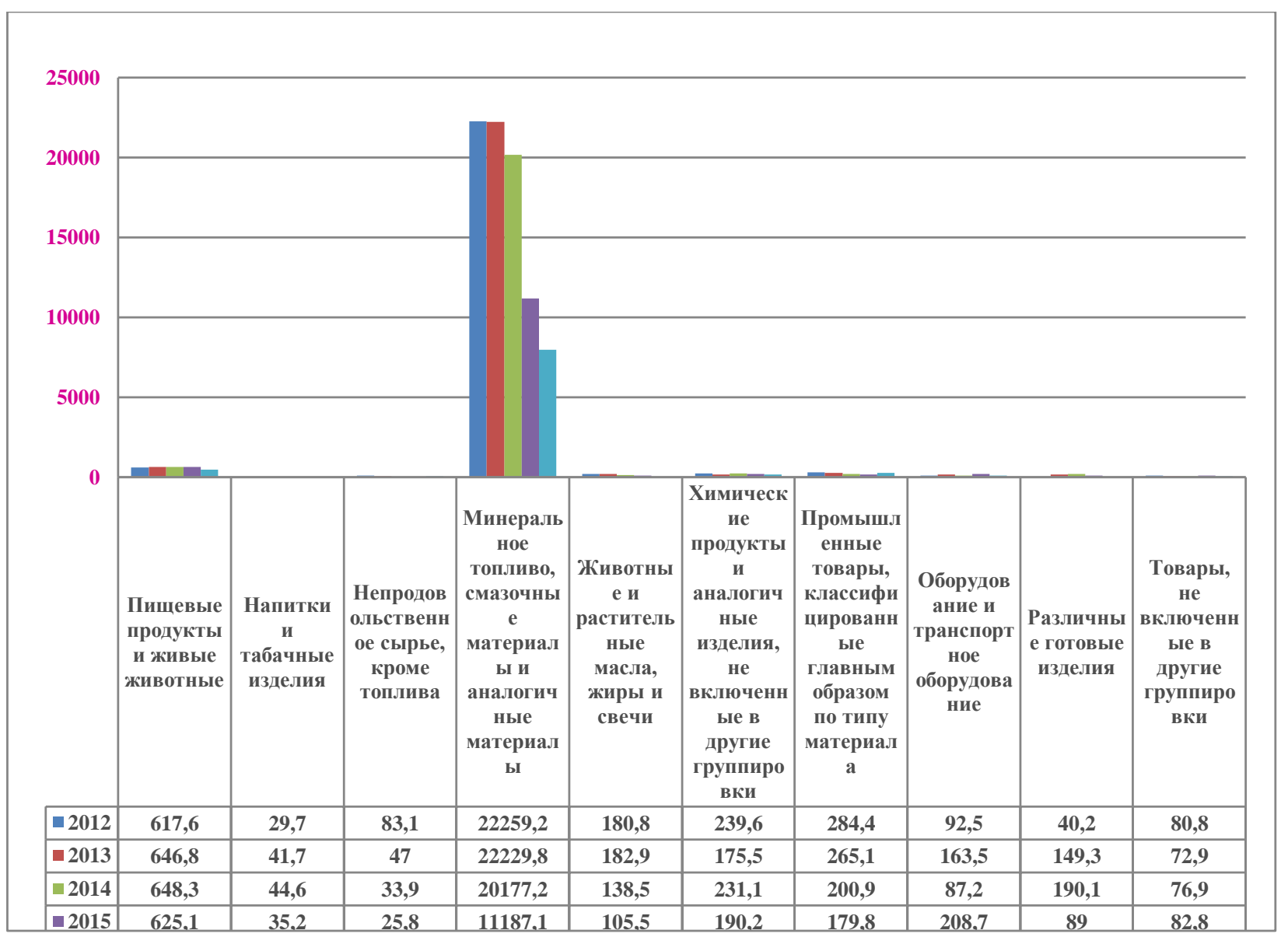

Рисунок 13 - Структура экспорта Азербайджана за 2012-2016 годы, млн. долл. США (подготовлено авторами на основе материалов Государственного Статистического Комитета Азербайджанской Республики, http://www.stat.gov.az).

А на Рисунке 14 дана структура экспорта Азербайджана за 2016 год в процентах по товарным группам. 


\begin{tabular}{|c|c|c|c|c|c|c|}
\hline Impact Factor: & $\begin{array}{l}\text { ISRA (India) } \\
\text { ISI (Dubai, UAE } \\
\text { GIF (Australia) } \\
\text { JIF }\end{array}$ & $\begin{array}{l}=1.344 \\
=0.829 \\
=0.564 \\
=1.500\end{array}$ & $\begin{array}{l}\text { SIS (USA) } \\
\text { PИНЦ (Russia) } \\
\text { ESJI (KZ) } \\
\text { SJIF (Morocco }\end{array}$ & $\begin{array}{l}=0.912 \\
=0.207 \\
=\mathbf{4 . 1 0 2} \\
=\mathbf{2 . 0 3 1}\end{array}$ & $\begin{array}{l}\text { ICV (Poland) } \\
\text { PIF (India) } \\
\text { IBI (India) }\end{array}$ & $\begin{array}{l}=6.630 \\
=1.940 \\
=4.260\end{array}$ \\
\hline
\end{tabular}

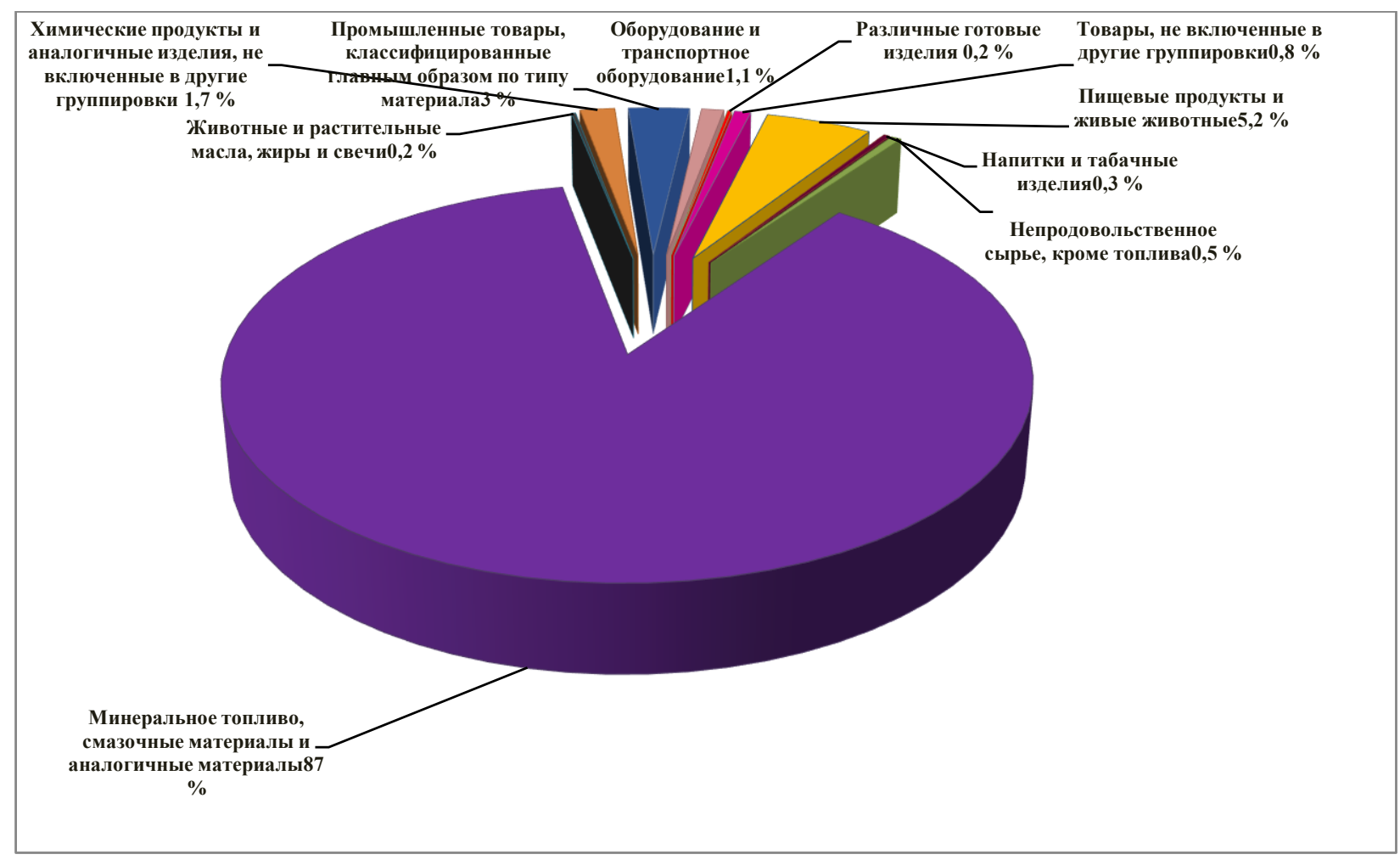

Рисунок 14 - Структура экспорта Азербайджана за 2016 год по товарным группам, в \% (подготовлено авторами на основе материалов Государственного Статистического Комитета Азербайджанской Республики, http://www.stat.gov.az).

Если анализировать Рисунок 14, то очевидна зависимость экспорта страны от нефти и нефтяных продуктов, которые за 2016 год составили 87 \% от общего объема экспорта страны.

\section{Conclusion}

В целом, следует отметить, что диверсификация внешнеторгового оборота Азербайджана пока полностью не отвечает требованиям и тенденциям глобального мира и обуславливает интенсификацию проводимых мероприятий по устранению барьеров и решению проблем для существенного повышения объема конкурентоспособных экспортных продукций на мировом рынке. Структура внешнеторгового оборота должна совершенствоваться за счет ненефтяного экспортного продукция [15].

Однако стоит подчеркнуть, что в рамках стратегического направления деятельности экономики страны за последние годы руководством и правительством страны принимались серьезные меры по диверсификации внешнеторгового оборота и, в том числе структуры экспорта Азербайджана [16]. Реализуются стратегические цели и задачи по диверсификации экспортного потенциала страны в рамках стратегических дорожных карт и мероприятий по стимулированию экспорта ненефтяных продукций. Созданы специальные электронные порталы по упрощению процедуры экспорта из Азербайджана [17]. С каждым годом наблюдается уменьшение зависимости экспортного потенциала от нефтяного фактора. Расширяется перечень конкурентоспособных и экспортоориентировочных продукций и товаров ненефтяных секторов страны. Например, за 2016-2017 годы заметилось увеличение экспорта фруктов и овощей, принимались меры по созданию национальных брендов. Только по экспорту помидора и фундука за 2017 год выручилось почти 300 млн. долл. США и, по мнению многих специалистов, эта часть потенциала ненефтяного сектора Азербайджана и имеется мощный потенциал по увеличению экспорта по десяткам видам ненефтяных продукций в ближайшей перспективе (химия и нефтехимия, металлургические продукции, продукция виноделия, хлопок - сырец, овощи, фрукты, растительное масло, прочее продукции аграрного сектора и т. д.). 


\begin{tabular}{l|lr|ll|ll} 
& ISRA (India) & $=\mathbf{1 . 3 4 4}$ & SIS (USA) & $=\mathbf{0 . 9 1 2}$ & ICV (Poland) & $=\mathbf{6 . 6 3 0}$ \\
Impact Factor: & ISI (Dubai, UAE) $=\mathbf{0 . 8 2 9}$ & PUHЦ (Russia) $=\mathbf{0 . 2 0 7}$ & PIF (India) & $=\mathbf{1 . 9 4 0}$ \\
& GIF (Australia) & $=\mathbf{0 . 5 6 4}$ & ESJI (KZ) & $=\mathbf{4 . 1 0 2}$ & IBI (India) & $=\mathbf{4 . 2 6 0}$ \\
& JIF & $=\mathbf{1 . 5 0 0}$ & SJIF (Morocco) $=\mathbf{2 . 0 3 1}$ & & \\
\hline
\end{tabular}

\section{References:}

1. Aliyev Sh.T. (2016) Kontseptual'nyye napravleniya usileniya eksportnogo potentsiala i promyshlennogo sektora v Azerbaydzhane // Zhurnal «Ipyak Yolu», №04, 2016. -p.35-42.

2. Aliyev Sh.T., Sazmani N.E. (2017) The problems of diversification of Azerbaijan's export potential in modern condition //Journal «International scientific review». Boston, USA, №02-2017. -p. 41-45.

3. Alive SH.T. (2017) Puti povysheniya eksportnogo potentsiala $\mathrm{V}$ realizatsii strategicheskikh dorozhnykh kart V Azerbaydzhane // Zhurnal «Audit», № 1, 2017.p.60-66.

4. Shakaraliyev A.SH., Shakaraliyev G. (2016) Ekonomika Azerbaydzhana: realii i perspektivy, Baku, «Turkhan», 2016.-536 p.

5. Shakaraliyev A.SH. (2009) Ekonomicheskaya politika gosudarstva: realii i perspektivy. Baku, 2009. $-416 \mathrm{p}$.

6. (2016) Ukaz Prezidenta Azerbaydzhanskoy Respubliki ob utverzhdenii strategicheskikh dorozhnykh kart po natsional'noy ekonomike i osnovnym sektoram ekonomiki. Gorod Baku, 6 dekabrya 2016 god. http://www.president.az.

7. (2016) Rasporyazheniye Prezidenta Azerbaydzhanskoy Respubliki o dopolnitel'nykh merakh po stimulirovaniyu eksporta neneftyanoy produktsii. Gorod Baku, 18 yanvarya 2016 god.

8. Aliyev SH.T. (2015) Vneshneekonomicheskaya politika Azerbaydzhana. Izdatel'stvo Sumgayytskogo Gosudarstvennogo Universiteta, 2015.-185 p.

9. Aliyev SH.T. (2012) Ekonomicheskaya diplomatiya. Baku, «Nauka i obrazovaniye», 2012.-196 p.

10. Ganbarov F.A. (2014) Vneshneekonomicheskiye obespecheniya ekonomicheskogo rosta Azerbaydzhana v usloviyakh globalizatsii. Avtorofererat diss.d-ra ekon. nauk. Baku, 2014. $-60 \mathrm{p}$.

11. Gul'aliyev M.G. (2016) Stepen' gosudarstvennogo vmeshantel'stva vo vneshnyuyu torgovlyu i yego makroekonomicheskoye vliyaniye // Zhurnal «Nauchnyye trudy», Institut Ekonomiki NANA, № 1, 2016. -p. 19-28.

12. Emir-Il'yasova E.I. (2013) Vneshneekonomicheskiye svyazi Azerbaydzhanskoy Respubliki v usloviyakh integratsii $\mathrm{v}$ mirovuyu ekonomiku. Diss. d-ra ekon. nauk. Baku, 2013.-48 p.

13. Aliyev E.V. (2015) Sovremennyy analiz eksporta Azerbaydzhana v Yevrosoyuz // Azerbaijan Journal of Economics and Social Studies/ Number 2, Volume 1, 2015.

14. Karimli I.A., Bayramov I.R. (2017) Sovershenstvovaniye valyutnogo kontrolya nad importno-eksportnymi operatsiyami Azerbaydzhana // Nalogovyy zhurnal. 1(133) / 2017.-p. 61-76.

15. Bayramov V. (2017) Vneshnetorgovyy oborot Azerbaydzhana. Sotsial'nyy i ekonomicheskiy tsentr razvitiya. Available: http://www.facemark.az. $\quad$ (Accessed: 10.01.2018).

16. (2017) Vneshnyaya torgovlya Azerbaydzhana. Statisticheskoye izdaniye. Baku, 2017.- 230 p.

17. Khankishchiyeva S. (2017) Natig Amirov: «Sozdannyy s initsiativoy Il'khama Aliyeva portal azexport.az nosit tseli usileniya pozitsii Azerbaydzhana». Available: http://www.1news.az. (Accessed: 10.01.2018). 